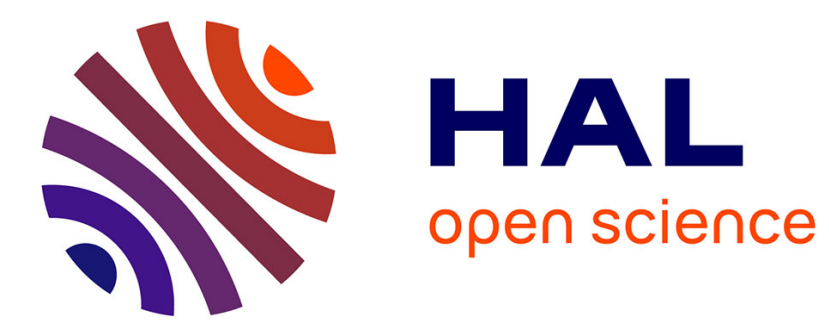

\title{
Generation of Supersonic Plasma Flow by Means of Unipolar RF Discharges
}

M. Novák, M. Sícha, V. Kapicka, L. Jastrabík, L. Soukup, Z. Hubicka, M. Klíma, P. Slavícek, A. Brablec

\section{- To cite this version:}

M. Novák, M. Sícha, V. Kapicka, L. Jastrabík, L. Soukup, et al.. Generation of Supersonic Plasma Flow by Means of Unipolar RF Discharges. Journal de Physique IV Proceedings, 1997, 07 (C4), pp.C4-331-C4-339. 10.1051/jp4:1997427 . jpa-00255583

\section{HAL Id: jpa-00255583 https://hal.science/jpa-00255583}

Submitted on 1 Jan 1997

HAL is a multi-disciplinary open access archive for the deposit and dissemination of scientific research documents, whether they are published or not. The documents may come from teaching and research institutions in France or abroad, or from public or private research centers.
L'archive ouverte pluridisciplinaire HAL, est destinée au dépôt et à la diffusion de documents scientifiques de niveau recherche, publiés ou non, émanant des établissements d'enseignement et de recherche français ou étrangers, des laboratoires publics ou privés. 


\title{
Generation of Supersonic Plasma Flow by Means of Unipolar RF Discharges
}

\author{
M. Novák, M. Šícha*, V. Kapička**, L. Jastrabík, L. Soukup, Z. Hubička*, M. Klíma**, P. Slıvíček** \\ and A. Brablec**
}

Institute of Physics, Division of Optics, Academy of Sciences of the Czech Republic, Na Slovance 2, 18040 Prague 8, Czech Republic

* Department of Electronics and Vacuum Physics, Faculty of Mathematics and Physics, Charles

University, V. Holešovičkách 2, 18000 Prague 8, Czech Republic

** Department of Physical Electronics, Faculty of Science, Masaryk University, Kotlárská 2,

61137 Brno, Czech Republic

\begin{abstract}
Recently the unipolar discharges has been used as a plasma source which employ the flow of the working gas for the creation of plasma channels: At first the radio frequency unipolar one hollow cathode discharge the cathode of which acts simultaneously as a nozzle for working gas inlet to the reactor chamber has been used in the particular applications. $[1,2\}$. On the base of this reactor the plasma-chemical reactor with a system of unipolar multi-hollow-cathode discharges has been developed. This reactor is able to deposit the composite thin films and multi-layer structures onto internal walls of cavities, tubes and on the components with complicated shapes. Secondly the RF unipolar torch discharge has been used as a source of the plasma channel. The advantage of this system is that it is possible to use it up to atmospheric pressure of the working gas and even in the liquid environment[3],[4]. In the present report the generation of the plasma channels by means of mentioned RF unipolar plasma discharges is discussed. At first the devices with RF unipolar hollow cathode discharge are presented and after that the device with the torch discharge is mentioned.
\end{abstract}

\section{RF LOW PRESSURE PLASMA CHEMICAL REACTOR WITH UNIPOLAR HOLLOW CATHODE DISCHARGE}

\subsection{The plasma-chemical reactor with one unipolar hollow-cathode discharge}

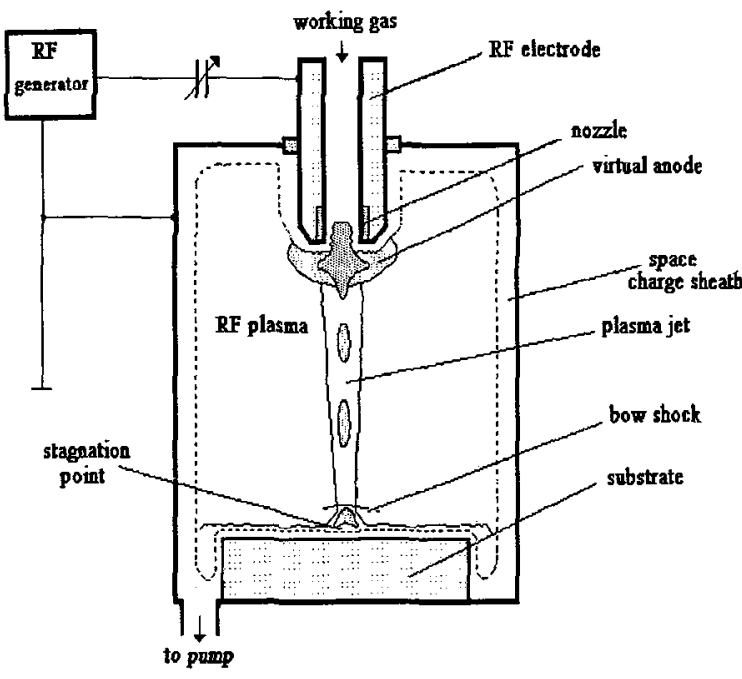

Fig.1. Schematic drawing of the unipolar hollow cathode discharge device.
In the plasma-chemical reactors with unipolar hollow cathode discharge $[1,5]$ the working gas flows through the hollow cathode which acts simultaneously for working gas as a nozzle. According to the working gas velocity in the hollow cathode these systems can be roughly divided into two groups: The system with subsonic working gas flow in the reactor chamber and with supersonic one (RPJ).

The unipolar hollow cathode discharge is induced by potential drop across the space charge sheath around the RF electrode. The space charge sheath is created by the customary two electrode RF discharge (Fig.1). The substrate is placed on the grounded electrode. The nozzle in the RF electrode connected with radiofrequency signal admits the working gas into the continuously pumped vacuum reactor.

At the RF power below a certain limit (for example $<20 \mathrm{~W}$ ) the value of the potential drop is not sufficient to induce the additional hollow-cathode discharge. In this case only an 


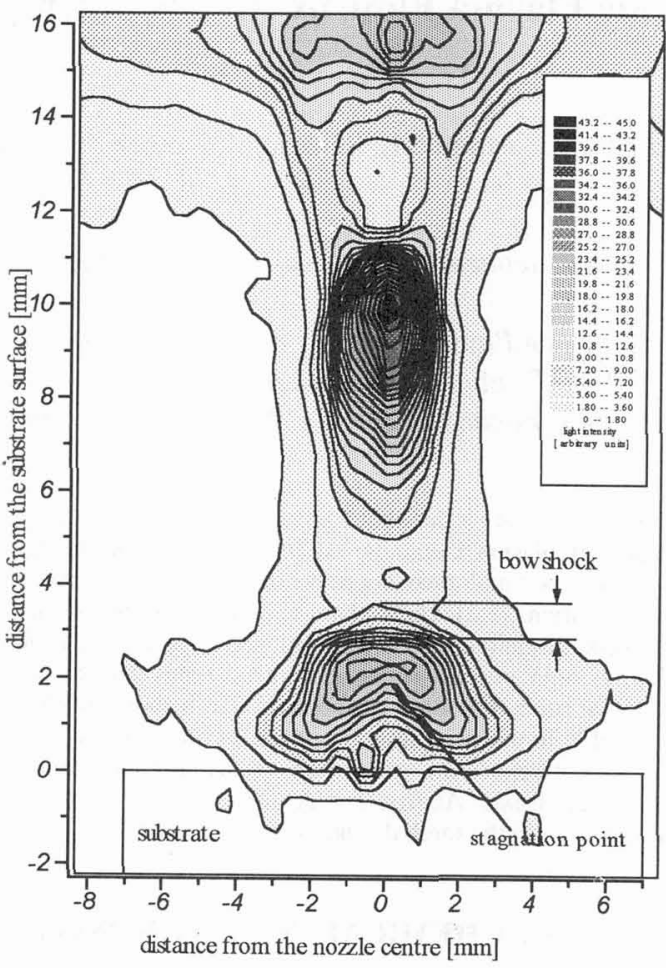

Fig 2. Lines of equal light intensity in the supersonic plasma jet channel. Working gas $\mathrm{N}_{2}$ pressure $75 \mathrm{~Pa}$, gas flow $900 \mathrm{sccm}, \mathrm{RF}$ power $60 \mathrm{~W}$

exceeds this limit the potential drop induces an intensive unipolar hollow cathode discharge inside the nozzle.

The potential drop across the space charge sheath around the powered RF electrode which is created by $\mathrm{RF}$ discharge represents the source of electromotive force for the unipolar hollow cathode discharge induced inside the nozzle. Because the RF power for generation of the RF plasma inside the reactor is fed to the electrode trough a serial capacitor the DC component of the unipolar hollow cathode discharge cannot flow trough external circuit. For this reason the virtual anode is created in the neighbourhood of the $\mathrm{RF}$ electrode. According to $[1,5,6]$ the AC current component also flows to the virtual anode.

The working gas pressure is maintained at several tens or hundreds of $\mathrm{Pa}$ and the working gas flow is adjusted in such a manner that the flow inside the reactor chamber is supersonic.

The incoming working gas forces this discharge supersonically from the nozzle into the reactor and a well-defined plasma jet channel is created inside the primary RF plasma [6,7]:(see Fig.2)

The simplified condition for the plasma jet generation has been described in [5]. The processes inside the nozzle are described with more precision in [1]. If we take into account the hollow cathode effect then 
according the paper [1] we obtain for the breakdown condition of the discharge inside the nozzle the following expression:

$$
\langle K\rangle=\frac{1+\gamma}{\gamma+G} \frac{1-\frac{G_{i s}}{\gamma}}{1-\frac{G_{i s}}{\gamma+G}} ;
$$

where:

$$
\langle K\rangle=\exp \left(\frac{i}{T} \int_{0}^{T} \int_{0}^{d} \alpha(x, t) d x d t\right),
$$

and $\alpha$ and $\gamma$ are the first and the third Townsend coefficients, $T$ is the period of the RF voltage, $d$ is the thickness of the cathode fall region inside the nozzle, the coefficient $G$ expresses the electron emission from the nozzle surface due to the hollow cathode effect and the coefficient $G_{i S}$ expresses the particular process of electrons secondary emitted from the nozzle surface by means of ions created by pendulum high energetic electrons inside the cathode fall region.

The described radio frequency plasma jet reactor with supersonic flow of the working gas inside the nozzle ( RPJ ) was developed for deposition of thin films into the hollow substrates and substrates of complicated shapes because the plasma channel is forced by supersonic flow to the substrate.

Depending on experimental conditions the nozzle outlet can be sputtered or evaporated by the hollow cathode discharge inside the nozzle. The deposition of the thin films can be carried out by two basic ways:

a.) Plasma Chemical Vapour Deposition (PCVD) when a mixture of reactive gas is activated in the plasma stream and the chemically activated species recombine on the substrate surface to form the thin film. Typical example of PCVD thin film deposition by means of RPJ is the deposition of the silicon nitride thin films. The working gas mixture is composed from nitrogen and $3 \%$ silane diluted in argon [8].

b.) Physical Vapour Deposition (PVD) when the components which are necessary for growth of the thin film is supplied by an erosion of the nozzle for example by reactive sputtering or by an arc evaporation. Typical example of (PVD) by means of RPJ deposition is deposition of the germanium nitride thin film [2]. In these cases has been experimentally found that by means of the RPJ reactor the thin films with defined stoichiometry have been achieved $\mathrm{Ge}_{3} \mathrm{~N}_{4}$ [2]. Recently thin films with defined stoichiometry have been obtained for $\mathrm{Cu}_{3} \mathrm{~N}[9]$ and $\mathrm{Al}_{2} \mathrm{O}_{3}$ [10] thin films.

\subsection{The plasma-chemical reactor with a system of unipolar multi-hollow-cathode discharges}

The results that have been obtained in the deposition of thin films by means of RPJ reactors with one unipolar hollow cathode discharge indicate, that the plasma-chemical reactor with multi-hollow-cathode system [11] should be able to deposit the composite thin films and multi-layer structures onto internal walls of cavities, tubes and on the components with complicated shapes. It can be also expected that this system could be able to deposit the composite thin films and multi-layer structures from various materials in dependence on the sort of working gases and nozzle's materials.

In the primary plasma channel and also inside the hollow cathode discharge takes place also the product of plasma-chemical reactions between the working gas particles and particles sputtered from the cathode. Therefore in the two primary plasma channels the intensive plasma-chemical reactions should be expected especially if the working gas is composed from several sorts of gases. This fact increases flexibility in the use of the reactor with multi-hollow-cathode system. 
Until now for sake of simplicity we used the reactor with only two hollow cathodes. The schematic

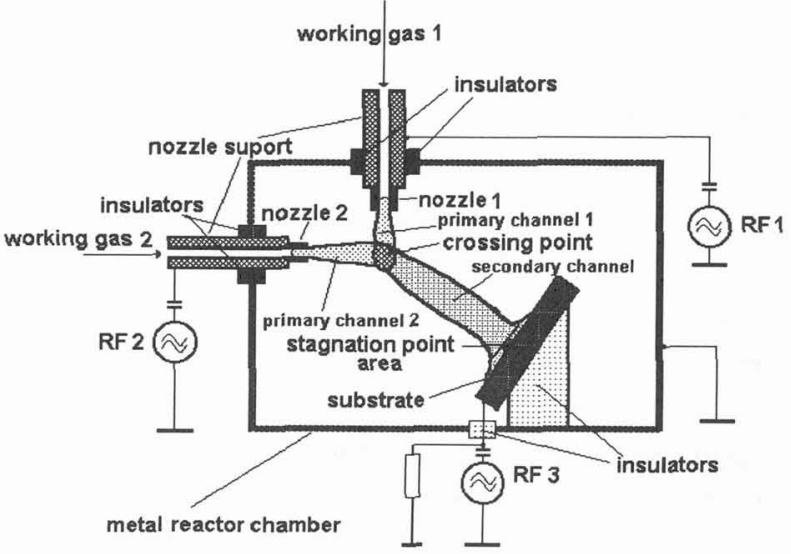

Fig. 3. Schematic drawing of the system of two unipolar hollow cathode discharges drawing of the experimental set up is shown in Fig. 3. The velocity of the working gases which flow through both nozzles were adjusted in such a manner that the flows from both nozzles are supersonic. Both nozzles are connected to the different RF generators (in Fig.3. generator RF1 and RF2). By means of these generators two plasma jets are created inside the reactor chamber in the same way as in one hollow cathode reactor. The advantage of such experimental set up is that both plasma-jet channels are created by independent sources and the working conditions of each

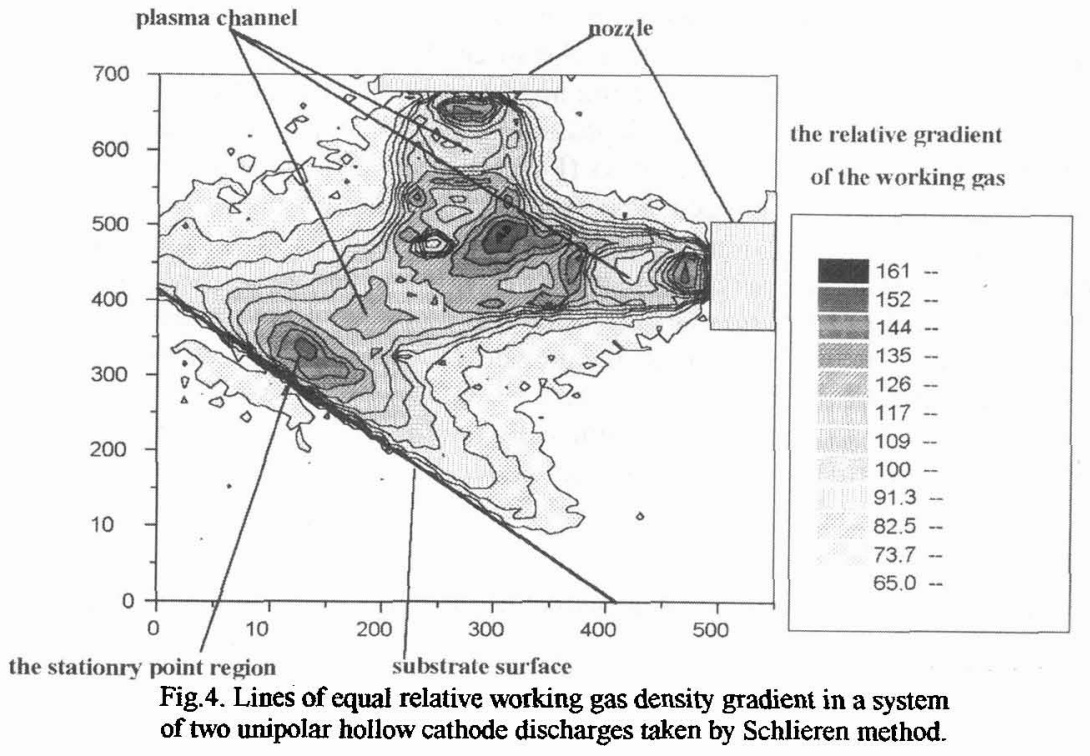

hollow cathode discharge and primary plasma-jet channels can be independently adjusted.

The substrate is isolated from the metallic wall of the reactor chamber and it is connected with the output of the third RF generator (in Fig 3. RF3). Within certain limits it is possible by means of the output voltage of this generator to adjust the self-bias voltage of the substrate.

In order to study the neutral gas flow in the plasma channels and in the crossing point we used the Schlieren method (for example [12]) supplemented by the CCD camera. The data processing computer software has been used in order to obtain the lines of the same value of the relative working gas density gradient and hence to get an idea of the structure of gas flows in the plasma channels and in the crossing point region.

An example of the experiment is shown on Fig.4. Experimental results presented in this figure show that if the gas flows in the primary plasma channels are supersonic in the crossing point of primary plasma 
channels the shock wave is created. This shock wave bend the primary channels to one direction and secondary plasma channel is created.

Furthermore experimentally has been found that the direction of the secondary plasma channel depends on the magnitude of the flows of working gases in the primary plasma channels (see Fig.4). It has been found that it is possible to deviate the secondary plasma channel by the variation of the gas flow (drift velocity) in both nozzles. The secondary plasma channel could be deviated up to $70^{\circ}$ from the vertical direction if the ratio of the flows in the horizontal nozzle with

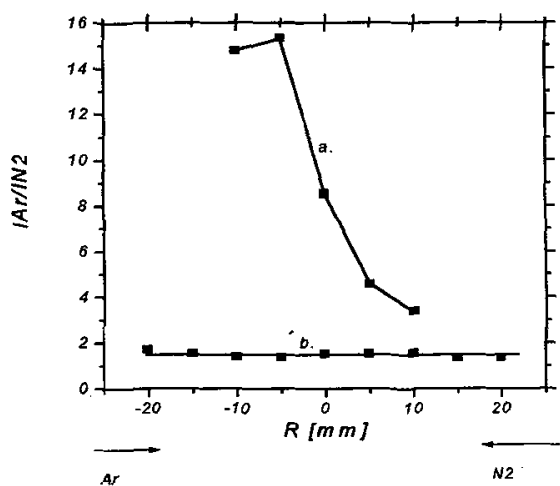

Fig. 5. Radial distributions of the ratio of the spectral lines of $\mathrm{Ar}$ and $\mathrm{N}_{2}$ across the crossing poit (a) and the stagnation point near the substrate (b). respect to the flow in vertical one increases approx. four times.

The deviation of the secondary plasma channel allowed to deposit the thin film in the defined part of the substrate. For this reason by means of the multi-hollowcathode system it is possible to deposit the composite thin films and multi-layer structures onto internal walls of cavities, tubes and on the components with complicated shapes.

In order to study the homogeneity of the secondary plasma channel argon and nitrogen have been used as working gases. The radial distributions of the ratio of the two spectral lines of $\operatorname{Ar}(826.4 \mathrm{~nm})$ and $\mathrm{N}_{2}(371 \mathrm{~nm})$ have been measured across the crossing point (see Fig.5(a)) and at the stagnation poinit near the substrate (see Fig. 5 (b)). From Fig. 5(b) it is seen that near the substrate the secondary plasma channel is homogeneous.

\subsection{The plasma-chemical processes in the plasma channels.}

The scheme of the particles and their interactions inside the reactor with the two-hollow-cathode system is presented in Fig.6. In the primary plasma channels due to hollow cathode discharges there are the neutral $\left(A_{1}, B_{1}\right)$, excited $\left(A_{1}^{*}, B_{1}^{*}\right)$ and ionised $\left(A_{1}^{+}, B_{1}{ }^{+}\right)$particles of the working gas and the particles sputtered from nozzle surface: $\left(\mathrm{A}_{2}, \mathrm{~B}_{2}, \mathrm{~A}_{2}{ }^{*}, \mathrm{~B}_{2}{ }^{*}, \mathrm{~A}_{2}{ }^{+}, \mathrm{B}_{2}{ }^{+}\right)$. Therefore in the two primary plasma channels and also inside the hollow cathode discharges intensive plasma-chemical reactions take place. That should be expected especially if the working gas is composed from several sorts of gases.

In the crossing point, in the secondary plasma channel and in the stagnation point (that is the point of the interaction between the substrate and the secondary channel) one should expect intensive plasmachemical reactions between the particles from both primary channels. This fact increases flexibility in the use of the reactor with multi-hollow-cathode system.

As an example of plasma-chemical reactions in the plasma channel the plasma-chemical ion-molecular reaction of ions $\left(\mathrm{A}^{+}\right)$with the neutral molecules $\left(\mathrm{B}_{\mathfrak{n}}\right)$ will be investigated in more detail. The intensity of the particular plasma-chemical ion-molecular reaction of ions $\left(A^{+}\right)$with the neutral molecules $\left(B_{n}\right)$ can be estimated under assumption that in the supersonic channel the plasma is approximately in the condition of the flowing afterglow. The radial diffusion of the particles does not play a substantial role due to supersonic axial velocity and shock waves on the boundary of the channel. The density of the neutral molecules $\left[\mathrm{B}_{n}\right]$ is customary several orders higher with respect to the density of ions $\left[\mathrm{A}^{+}\right]$so that the variation of the density $\left[\mathrm{B}_{\mathrm{n}}\right]$ due to reactions with ions $\left(\mathrm{A}^{+}\right)$can be in our estimation neglected. Then for the variation of the ion density $\left[\dot{A}^{+}\right]$along the secondary channel can be written assuming that radial diffusion is negligible:

$$
\frac{d\left[A^{+}(t)\right]}{d t} \approx-k_{r}\left[A^{+}(t)\right]\left[B_{n}\right]
$$


where $\left[\mathrm{A}^{+}\right]$and $\left[\mathrm{B}_{\mathrm{n}}\right]$ are the densities of ions and molecules respectively, $\mathrm{k}_{\mathrm{r}}$ is the rate coefficient of the ionmolecular reaction between $\mathrm{A}^{+}$and $\mathrm{B}_{\mathrm{n}}$.

The solution of the equation (3) is:

$$
\left[A^{+}(t)\right] \approx\left[A^{+}(0)\right] \exp \left\{-k_{r}\left[B_{n}\right] t\right\}
$$

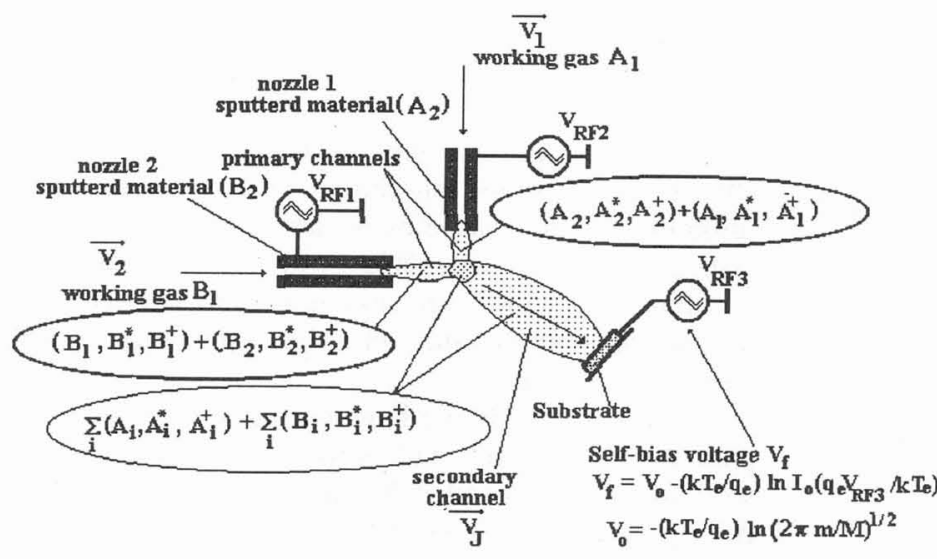

Fig.6. Scheme of particles and their interactions inside the two-hollowcathode system

where $t$ is the reaction time and $\left[\mathrm{A}^{+}(0)\right]$ is the density of the ions in the crossing point. Because the plasma in the secondary channel is flowing with drift velocity $V_{D}$ for the reaction time $t$ can be approximately written:

$$
t \approx \frac{x}{V_{D}}
$$

$x$ is the distance from the crossing point where the reaction time is $t=0$.

By means of equation (4) it is possible to determine the decay of the ion density $\left[\mathrm{A}^{+}\right]$due to reactions with molecules $\left(B_{n}\right)$

and from obtained results roughly estimate the intensity of the investigated ion molecular reactions.

For example we assume that the rate coefficient $\mathrm{k}_{\mathrm{i}}$ of the investigated ion-molecular reaction is of the order of $10^{-9} \mathrm{~cm}^{3} \mathrm{sec}^{-1}$, the density of the neutral molecules $\left[\mathrm{B}_{\mathrm{n}}\right]$ is of the order of $10^{14}-10^{16} \mathrm{~cm}^{-3}$. The density of the ions $\mathrm{A}^{+}$in the secondary channel decreases on $1 \%$ of the value on the beginning of the channel $\left[\mathrm{A}^{+}(0)\right]$ (in the crossing point) after the reaction time of about $t \approx 0,04-40 \mu \mathrm{sec}$. For supersonic velocity of the particles in the secondary plasma channel the average drift velocity is of the order of $V_{D} \approx 3.10^{4} \mathrm{~cm} / \mathrm{sec}$. If we assume the distance between substrate and crossing point in the order of several $\mathrm{cm}$ the life time of the particles in the plasma channel is of the order of several tenth till hundred $\mu \mathrm{sec}$. For the exact calculations of the reaction intensity along the channel it is necessary to take into account the recombination, the radial diffusion of the ions $\mathrm{A}^{+}$and also the variation of the drift velocity in the supersonic channel. Nevertheless from above mentioned simplified consideration it could be seen that the density of the reaction product at the end of the secondary channel reaches the value which is in the order approximately the same as the value $\left[\mathrm{A}^{+}\right]$of ion density at the beginning of the channel.

By means of the above presented considerations dealing with plasma-chemical processes in the plasma channels could be explained the experimental fact that by means of the reactor with hollow cathode it is possible to deposit thin films with defined stoichiometry. As it has been mentioned above up to now the $\mathrm{Ge}_{3} \mathrm{~N}_{4}$ [2] and more recently the $\mathrm{Cu}_{3} \mathrm{~N}$ [9], and $\mathrm{Al}_{2} \mathrm{O}_{3}$ [10] stoichiometric thin films have been achieved.

\section{THE HIGH PRESSURE TORCH DISCHARGE PLASMA SOURCE}

This plasma source is based on the RF arc torch discharge. For this reason we will at first shortly describe the phenomena of the RF corona and the torch discharge and the transition of the corona to the torch discharge and transition to the arc torch discharge. Furthermore the plasma source which employ the high pressure RF torch discharge will be described. 


\subsection{The RF corona and the torch discharge}

Generally the RF corona discharge is generated due to the strong intensity of the RF electric field in the neighbourhood of a sharp electrode edge where the discharge originates. This fact is confirmed by the spectrum of the discharge. Thus the main ionisation processes of neutral particles in the RF corona discharge are the ionisation collisions of the electrons accelerated in the strong electric field region.

When the RF power dissipated in the discharge in the polyatomic working gas increases then the vibrational temperature of excited neutral molecules also increases $[13,14]$. Due to the increase of the vibrational temperature increases also the role of thermal ionisation of the excited neutral molecules (with higher vibrational temperature). This thermal ionisation causes the decrease of the electric field intensity in the neighbourhood of the electrode and as a consequence also the ionisation caused by accelerated electrons decreases. In the region where the electron temperature and the vibrational temperature of the excited neutral molecules takes approximatelly the same value the corona discharge transits to the torch discharge. The transition between the corona and the torch discharge is not abrupt, but gradual [13,14]. At small RF power absorbed in discharge the discharge corresponds to the corona discharge while at higher power the torch discharge occurs. In Fig. 7 it is seen the dependence of neutral particles and electron temperatures on the RF power in the transition region between the corona and the torch discharge. The plasma of the torch discharge in the monoatomic working gas differs from that burning in the polyatomic gases. The transfer of the electron energy to the neutral particles in this case has been studied in [15]

When the RF power which is dissipated in the torch discharge increases above certain limit at which the temperature of the sharp electrode edge is so high that the electrode material is evaporated the plasma of the torch discharge is formed in the mixture of working gas and vapours of the evaporated electrode material. The properties of such torch discharge do not resemble those of a glow discharge but they are more like those of an arc discharge. For this reason it is necessary to consider such torch discharge as the arc torch discharge $[14,16]$.

\subsection{The plasma source with the arc torch discharge}

The scheme of the experimental set up $[3,4]$ is shown in Fig 8 . The powered electrode of the arc torch discharge is made from the thin pipe the inner diameter of which is $1-2 \mathrm{~mm}$ and lenght several $\mathrm{cm}$. The support for the electrode has been cooled by flowing water. The electrode was connected trough the

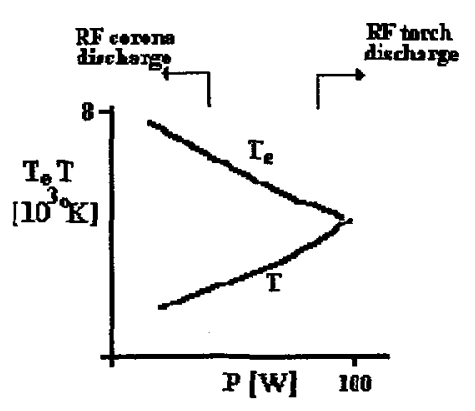

Fig. 7.Dependence of the neutral particles (T) and electron $\left(T_{e}\right)$ temperatures on the $R F$ power

the primary $\mathrm{RF}$ plasma inside the reactor matching unit to the RF generator the frequency of which was $13,56 \mathrm{MHz}$. The RF power absorbed in torch discharge has been adjusted in such a manner that at the electrode edge the arc torch discharge was created. The working gas which flows from the nozzle stabilizes the arc torch discharge and well-defined plasma channel is created downstream the gas flow. It is important to notice that for generation of the plasma channel at the atmospheric pressure it is not necessary to place the torch arc discharge electrode nozzle inside the closed plasma-reactor chamber.

The pressure in our reactor chamber was maintained in the range approx. from $10^{3} \mathrm{~Pa}$ up to atmospheric pressure. In such pressure range the nozzle of the powered electrode (thin pipe) cannot act as a hollow cathode [17] and only the edge of the electrode is involved in the discharge processes. Due to this phenomenon the torch plasma source differs from the source in the reactor with the hollow cathode $[1,5]$ in which cathode. 
For atmospheric pressure of the working gas the RF power absorbed in torch discharge has been adjusted above $100 \mathrm{~W}$ and so at the electrode edge the arc torch discharge was created. At lower pressure

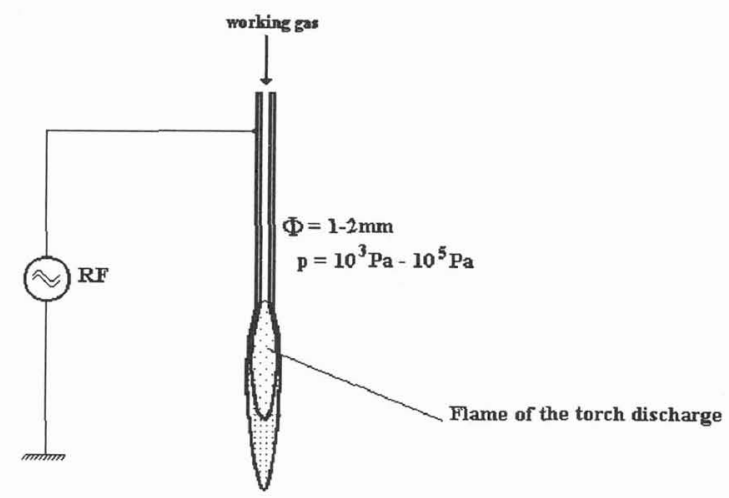

Fig. 8. Schematic drawing of the torch discharge device. approx. $10^{3} \mathrm{~Pa}$ the RF power which was necessary to create the arc torch discharge was in the order of several tens of watts.

The vibrational and rotational temperature at the axis of the plasma channel inside the reactor have been determined by means of the optical plasma diagnostic method. During this measurements the reactor output was open and the air as working gas was thus maintained at the atmospheric pressure. The gas which flowed trough the electrode nozzle was argon. Thus the plasma channel was created in the mixture of air and argon. The vibrational temperature which was assumed to be close to the electron temperature has been determined from molecular band of $\mathrm{N}_{2}$ second positive system. The magnitude of the vibrational temperature has been found approx. $T_{v} \approx 2000 \mathrm{~K}$. For rotational temperature which was determined from the $\mathrm{OH} 306,4 \mathrm{~nm}$ band has been found the magnitude approx. $\mathrm{T}_{\mathrm{r}}$ $\approx 500 \mathrm{~K}$. The rotational temperature was assumed to be close to the temperature of the neutral gas in the place of the discharge.

The plasma source with the arc torch discharge can be fasten in the dielectric holder and used for surface treatments as a "RF plasma pencil". Up to now such plasma pencil has been used for treatment of archaeological artefacts in liquid environments [4].

\section{Acknowledgements}

This work has been done in frame of the Association for Education, Research and Application in PlasmaChemical Processes and was financially supported by grant 202/95/1222 of Grant Agency of Czech Republic and by project COST $515^{\circ} .50$.

\section{References}

[1] M. Śícha, L. Soukup, L. Jastrabík, M. Novák, M. Tichý, Surface and Coatings Technology 74-75 (1995) 212

[2] L. Soukup, V. Peřina, L. Jastrabík, M. Šícha, P. Pokorný, R.J. Soukup, M. Novák,J. Zemek, Surface and Coating Technology, (1996) 280

[3] A.Brablec, P. Slavíček, M. Klíma, V. Kapička, Proc. 18th Symposium on Plasma Physics and Technology Prague (1997) 193

[4] Klíma M., Janča J., Zajičková L., Brablec A., Sulovský P., Alberti M., Proc. 18th Symposium on Plasma Physics and Technology Prague (1997) 285

[5] Sícha M., Bárdoš L., Tichý M., Soukup L., Jastrabík L., Baránková H., Soukup R.J., Touš J., Contrib. Plasma Phys.34 (1994) 794.

[6] M. Tichý, M. Šícha, L. Bárdoš, L. Soukup, L. Jastrabík, K. Kapoun, J. Touš, Z. Mazanec, R.J. Soukup, Contrib. Plasma Phys. 34 (1994) 765 
[7] M. Sícha, Z. Hubička, M. Tichý, M. Novák, L. Soukup, L. Jastrabík, J.F. Behnke, V. Kapička, K. Kapoun, M. Šerý, Contrib. Plasma Phys. $36(1996) 605$

[8] L. Bárdoš, V. Dušek, Thin Solid Films 159 (1988) 265

[9] L. Soukup, L. Jastrabík, M. Sícha, Z. Hubička, M. Novák, H. Síchová, F. Fendrych, V. Valvoda, The deposition of the $\mathrm{Cu}_{3} \mathrm{~N}$ thin films by means of hollow cathode plasmachemical reactor. (to be published)

[10] L. Soukup, L. Jastrabík, M. Sícha, Z. Hubička, M. Novák, H. Síchová,

F. Fendrych, V. Valvoda, The deposition of the $\mathrm{Al}_{2} \mathrm{O}_{3}$ thin films by means of hollow cathode plasma-chemical reactor (to be published)

[11] Z. Hubička, M.Š́cha, M. Novák, L. Soukup, L. Jastrabík, K. Kapoun, M. Šerý, V. Kapička, The RF Plasma-Chemical Reactor with the System of Multi-Hollow-Cathodes for the Surface and Coating Technologies (to be published).

[12] Plasma Diagnostics Technigues, (ed. Huddelstone R.H., Leonard S.L.), Academic Press, New York, London, (1965)

[13] El Gammal M., Proc. VIII. ICPIG (Contributed papers) Vienna (1967) 237.

[14] Truneček V., Proc. Conf. Unipolar High-Frequency Discharges, Brno (Folia Sci. Nat. University Brno, Physica ) (1971) 3.

[15] Janča J., Folia Fac. Sci .Nat. University Brno, 9 (1968) 31.

[16] Popov V., Stolov A. L., Učon. Zap. Kazan. Univerziteta, Kazan 113 (1953) 53 (in russian).

[17] Delcroix H. I., Mino H., Popovici C., Proc. Int. Conf. Hollow Cathode Discharge Appl. ( 1971) 18 